\title{
Resignificación de los vínculos sociales durante la pandemia de COVID-19: narrativas de personas que convergen en Conjuntos residenciales en Bogotá, Colombia
}

\author{
Andrea Marcela Reyes-García \\ Trabajadora social \\ Universidad Colegio Mayor de Cundinamarca. Bogotá, Colombia \\ https:/ / orcid.org/0000-0002-4995-007X•abuha77@gmail.com
}

\section{Laura Daniela Molina-Ortiz}

Trabajadora social

Universidad Colegio Mayor de Cundinamarca. Bogotá, Colombia

https:/ / orcid.org/0000-0001-5921-5514 • ldanielamolina@unicolmayor.edu.co

Resumen

Este artículo describe el proceso de investigación que gira en torno a la resignificación de los vínculos sociales en las narrativas de dos conjuntos residenciales: Arboleda I y Casablanca etapa II de la ciudad de Bogotá D.C, durante la COVID-19. Para ello, se reconoce la situación actual señalando las concepciones básicas orientadas a la COVID-19, desde los elementos de su surgimiento, su expansión, las medidas tomadas por el gobierno colombiano, así como la actitud de la sociedad civil en conjuntos residenciales. El artículo cubre la comprensión de las subjetividades de los actores que con sus voces relatan sus experiencias en torno a los vínculos sociales, resaltando la singularidad de la comunidad, los aspectos organizacionales y los medios tecnológicos, entre otros. La metodología utilizada es de carácter cualitativo, en la línea de investigación narrativa; posteriormente, con un análisis relacional se conduce a unos resultados que ponen en evidencia las distintas modificaciones que han vivido los habitantes en la forma de vincularse a nivel filial, la participación selectiva, orgánica y de ciudadanía en momentos de emergencia sanitaria.

Palabras clave: Conjuntos residenciales; Narrativas; Vínculos Sociales; Comunidad; Sindemia COVID-19.

Recibido: 30/08/2021 | Aprobado: 09/09/2021 | Publicado: 01/01/2022

c) (i) (2) Esta obra está bajo una Licencia Creative Commons Atribución-NoComercialCompartirIgual 4.0 Internacional.

Financiación o proveniencia del artículo: Artículo derivado del proyecto de investigación COVID-19 y desigualdad social realizado en el periodo 2020-2021, avalado por la Universidad Colegio Mayor de Cundinamarca, Bogotá, Colombia.

\section{¿Cómo citar este artículo? / How to quote this article?}

Reyes-García, A. M., y Molina-Ortiz, L. D. (2022). Resignificación de los vínculos sociales durante la pandemia de COVID-19: narrativas de personas que convergen en Conjuntos residenciales en Bogotá, Colombia. Prospectiva. Revista de Trabajo Social e intervención social, (33), 143-169. doi: 10.25100/prts.v0i33.11567. 
Reyes-García y Molina-Ortiz

\title{
Redefinition of Social Ties During the COVID-19 pandemic: Narratives of People who Relate with Each Other in Gated Communities
}

\begin{abstract}
This article describes the research process that revolves around the resignation of social ties in the narratives of two residential complexes: Arboleda I and Casablanca stage II of the city of Bogotá D.C, during the COVID-19. To this end, the current situation is recognized by pointing out the basic conceptions oriented to the COVID-19, from the elements of its emergence, its expansion, the measures taken by the Colombian government, as well as the attitude of civil society in residential complexes. The article covers the understanding of the subjectivities of actors who with their voices relate their experiences around social ties, highlighting the uniqueness of the community, organizational aspects, and technological means, among others. The methodology used is qualitative, in the line of narrative research; Subsequently, a relational analysis leads to results that show the different modifications that the inhabitants have experienced in the way of linking at the branch level, selective, organic and citizen participation in times of health emergency.

Keywords: Residential complexes; Narratives; Social ties; Community; Syndemic COVID-19.

Sumario: 1. Introducción, 2. Contexto de la COVID-19 en Bogotá, Colombia, y los Conjuntos residenciales Arboleda I y Casablanca etapa II, 3. Referentes conceptuales, 3.1 Comunidad, 3.2 Vínculos Sociales, 3.3 La COVID-19, 4. Metodología, 5. Hallazgos, 5.1 Vínculo filial, 5.2 Vínculo de participación electiva, 5.3 Participación orgánica, 5.4. Vínculo de Ciudadanía, 6. Conclusiones, 7. Referencias bibliográficas.
\end{abstract}




\section{Introducción}

En la historia, el ser humano ha hecho frente a diversos acontecimientos en torno a la salud; de allí que, la transmisión de enfermedades zoonóticas ${ }^{1}$ cubre un $60 \%$ del total de todas aquellas que afectan la vida, como lo interpretan Andreatta, Navarro y Pezzetta (2020). Para ello, se ha estipulado a nivel internacional una categorización de las enfermedades de acuerdo con su expansión por los territorios. De allí que, la COVID-192 aunque se ha considerado como una pandemia "un brote epidémico afecta a regiones geográficas extensas como varios continentes" (De Rezende, 1998, p. 154); no hay que olvidar que las enfermedades están conectadas a las condiciones sociales. De esta manera, en la sindemia, interpretando a Muñoz-Rojas (2020), no sólo intervienen elementos biológicos en una enfermedad o más enfermedades, sino que además existen factores sociales, como la desigualdad social, que están presentes en la misma.

Teniendo en cuenta lo anterior, el descubrimiento de la COVID-19 empezó a ser de interés para organizaciones, asociaciones, gobierno, instituciones académicas, etc., que buscan establecer características propias del virus, resaltando sus síntomas comunes y graves, su forma de transmisión y la manera de abordarlo (Organización Panamericana de la Salud [OPS], 2020), centrándose en la enfermedad y las validaciones estadísticas o tecnológicas, las cuales refuerzan el aspecto cientificista, desde estudios en el área de la salud como los artículos de Bai et al. (2020) denominado Presumed Asymptomatic Carrier Transmission of COVID-19, así como el escrito de CDC COVID-19 Response Team, (2020) titulado Severe Outcomes Among Patients with Coronavirus Disease 2019 (COVID-19), United States y el texto de Velavan \& Meyer (2020) reconocido como The COVID-19 epidemic.

Sin embargo, cabe resaltar que las ciencias sociales colocan en el centro los interrogantes que se van generando sobre el alcance social de la COVID-19. En relación a ello, el estudio de Mesa y Alonso-Cano (2020) denominada Narrativas y discursos en tiempos de pandemia: cómo explicar la crisis del COVID-19, desde el feminismo pacifista, manifiesta una reflexión de la disputa por controlar el relato que polariza en ese tiempo; también el estudio de Rodríguez (2020), en Chile denominado Coronavirus: conexiones ocultas, narrativas Entretejidas, presenta la existencia de múltiples narrativas que se han entretejido desde su aparición, como lo son, las teorías conspirativas, una gripe común, la mortalidad sólo del $2 \%$, el cambio climático versus el coronavirus, gero-indiferentes y el discurso científico.

1 Las "enfermedades zoonóticas son un grupo de enfermedades infecciosas que se transmiten de forma natural de los animales a los seres humanos" (Organización Mundial de la Salud [OMS], 2020b).

2 A finales del mes de diciembre de 2019, como lo refiere He, Deng \& Li (2020) en la provincia de Hubei, Wuhan, China se notifican los primeros grupos de casos de neumonía de carácter desconocido, identificándolo así como un nuevo coronavirus; dicho virus, fue nombrado inicialmente por el Comité Internacional de Taxonomía de Virus como SARS-Cov-2, posteriormente la OMS lo llamó virus 2019-nCoV; aunque la neumonía, que es causada por esta infección viral, fue designada neumonía por coronavirus acogiendo la denominación de Covid-19. 
Reyes-García y Molina-Ortiz

Por otra parte, se sitúa en los estudios de la COVID-19 y las resignificaciones sociales que se han manifestado en los primeros meses de confinamiento, con la investigación de Fradejas-García, Lubbers, García-Santesmases, Molina y Rubio-Ros (2020) denominada las Etnografías de la pandemia por coronavirus: emergencia empírica y resignificación social, que cuestiona el control o no de los cuerpos, las relaciones afectadas por el encierro, imaginarios del futuro, entre otras; de igual forma, el artículo de Pleyers (2020) denominado los Movimientos sociales y la batalla por el significado de la crisis del coronavirus, refiere la lucha que ejercen diversos actores sociales sobre los significados que se le brinda a la crisis por la COVID-19.

En cuanto a Colombia, debemos mencionar la investigación realizada por AmézquitaTorres (2020) titulada Trabajo Social, emociones políticas y ética del cuidado en tiempos de COVID19 y el discurso como cuidado en la salud mental en la ciudad de Bogotá, con un acercamiento alrededor de las emociones gestadas en la sociedad a partir de la difusión que los medios de comunicación realizan sobre las medidas de contingencia. Así mismo, Ospina et al. (2020) con el estudio Afectación del COVID-19 en Bogotá D.C, establecieron el objetivo de comparar y contrastar las variables y percepciones de la pandemia COVID-19 de los habitantes en las localidades de Bogotá D.C.

Estos estudios evidencian el papel fundamental de las narrativas durante la Covid-19 y su significado en la cotidianidad. Por esta razón, la investigación acogió las narrativas, la resignificación, en los conjuntos residenciales. Ahora bien, los conjuntos residenciales, se han abordado en aspectos de convivencia, gobernabilidad, desobediencia civil, transformaciones socioespaciales, seguridad, lo financiero, etc., por ejemplo, los trabajos de Rincón-Salazar (2018), Echeverry-Velásquez y Prada-Dávila (2017), González-Serna (2016), Martínez-Toro (2016), Roitman (2016), Vidal-Koppmann (2001), entre otros autores. Aun así, no se han considerado los vínculos sociales que se establecen en dicho espacio o las narrativas que allí se proyectan, sobre todo en un momento que es marcado por la COVID19. Por lo tanto, este estudio giró en torno a la resignificación de los vínculos sociales en los conjuntos residenciales a partir de narrativas de las personas que convergen en Arboleda I y Casablanca etapa II durante la COVID-19, en el año 2020.

En el segundo apartado del artículo se presenta el contexto de la COVID-19 en Colombia, Bogotá y los Conjuntos Residenciales Arboleda I y Casablanca etapa II; luego el tercer apartado, con los referentes conceptuales, el cuarto apartado con la metodología que se aplicó en la investigación y da paso al quinto apartado de los hallazgos, con una descripción breve de los diferentes tipos de vínculos sociales. Culminando con el sexto apartado de conclusiones brindando una visión hacia próximas líneas de investigación y campos de intervención del Trabajo Social. 
Reyes-García y Molina-Ortiz

\section{Contexto de la COVID-19 en Bogotá, Colombia, y los Conjuntos residenciales Arboleda I y Casablanca etapa II}

En Colombia, el 6 de marzo de 2020 el Ministerio de Salud y protección social (2020b) confirmó el primer caso de la COVID-19 en la ciudad de Bogotá D.C, en una mujer de 19 años procedente de la ciudad de Milán, Italia, país que, simultáneamente, se consideraba con más contagios y muertes en el mundo. Desde esta fecha, el presidente y los alcaldes establecen acciones de cuarentena obligatoria por ejemplo la desarrollada del 20 hasta el 23 de marzo del 2020, del 25 hasta el 13 de abril de 2020 (Alcaldía Mayor de Bogotá, 2020b), del 4 de mayo hasta el 25 de mayo del 2020; igualmente, un aislamiento que perdura hasta el 15 de julio del 2020 (Presidencia de la República de Colombia, 2020); la creación de un sitio web estatal denominado Coronavirus Colombia (2020) para el mes de abril del 2020, el cual, recopila e ilustra los datos a nivel global, nacional, departamental y municipal en relación con la COVID-19 en el país.

Simultáneamente en Bogotá, en palabras de la cadena televisa TRT (2020), desde el 13 de julio y hasta el 23 de agosto, se da inicio al esquema de cuarentena basado en el cierre de las 20 localidades $^{3}$ de acuerdo con la velocidad de propagación del brote de la COVID-19. Esta medida se refuerza con el comunicado de presidencia del 28 de julio con el aislamiento preventivo hasta el 31 de agosto; además, el programa de Colombia Sigue Adelante, las alocuciones, declaraciones del presidente transmitidas por las cadenas televisivas públicas y privadas, finalizando con la recopilación de decretos, protocolos del gobierno justificándose en la mitigación de la transmisión de la COVID-19, cambiando el diario vivir de la población en torno a los vínculos que se establecen con sectores de la salud, educación, vivienda, económico, cultural, político o social.

En este camino, se presenta a continuación una breve descripción de cada localidad en la que se inscribió el proyecto.

1. La localidad de Kennedy $N^{0}$ 8: a principios de la sindemia se reconocía como una localidad de alto riesgo de contagio, lo cual llevó a las autoridades gubernamentales a tomar medidas de cuarentena sectorizadas. En este punto se presenta un debate entre diversos actores sociales de la ciudad para considerar dicho riesgo, ante argumentos de desobediencia en el cumplimiento de la cuarentena obligatoria, sin considerar problemáticas sociales que afectaban antes de la llegada del coronavirus, como lo expone la trabajadora social Adriana, residente de la localidad y trabajadora con jóvenes en situación

3 Es una unidad estadística de división territorial; de igual forma se percibe la localidad como un elemento básico para el análisis de la definición del desarrollo en el territorio (Consejo Nacional de Población, 2010, p. 17) 
Reyes-García y Molina-Ortiz

de vulnerabilidad en entrevista con Sardiña (2020). En su UPZ ${ }^{4}$ Kennedy Central junto al barrio Casablanca etapa II, se ubica el conjunto residencial Casablanca etapa II, el cual está conformado por 9 bloques de apartamentos divididos cada uno por 3 interiores que a su vez seccionan 16 apartamentos por interior, en total, la urbanización cuenta con 432 apartamentos.

2. La localidad de San Cristóbal N4: según las palabras del Canal Capital (2020), se conforma un comité especial de gerencia COVID-19 en el mes de mayo del 2020, encargado de afrontar la propagación del virus en el sector y fortalecer los mensajes de prevención, cuidado y autocuidado, siendo el sector con menores tasas de contagio. En la UPZ Sosiego y el barrio Quinta Ramos, se sitúa el conjunto residencial Arboleda I, compuesta por 4 interiores junto a 72 apartamentos.

Asimismo, los dos conjuntos se encuentran en el estrato 3, con servicios públicos y privados y son de fácil acceso; comparten, una estructura administrativa constituida por un administrador del conjunto, consejo de administración, comité de convivencia, realización de asamblea de copropietarios, trabajadores para el mantenimiento de la propiedad, personal de seguridad, zonas comunes que integran, zona verde, plazoleta, salón comunal para reuniones o eventos de los propietarios o copropietarios del conjunto. Allí residen familias conformadas por niños, niñas, jóvenes, adultos y adultos mayores; se puede identificar que las mujeres son la población predominante, de igual manera profesionales con ocupaciones independientes.

Siguiendo el hilo, es menester distinguir que estos conjuntos acogen las medidas expedidas por la Alcaldía Mayor de Bogotá (2020a), para la COVID-19, las cuales se describen a continuación:

4 Unidades de Planeamiento Zonal: según la Cámara de Comercio de Bogotá (CCB, s.f.) están identificadas como áreas urbanas más pequeñas que las localidades y más grandes que el barrio, de igual forma se reconocen como unidades territoriales o sectores necesarios para la planificación del desarrollo urbano en las diferentes zonas. 
Reyes-García y Molina-Ortiz

Figura 1. Medidas tomadas por administradores, consejos de administración y residentes de los conjuntos residenciales.

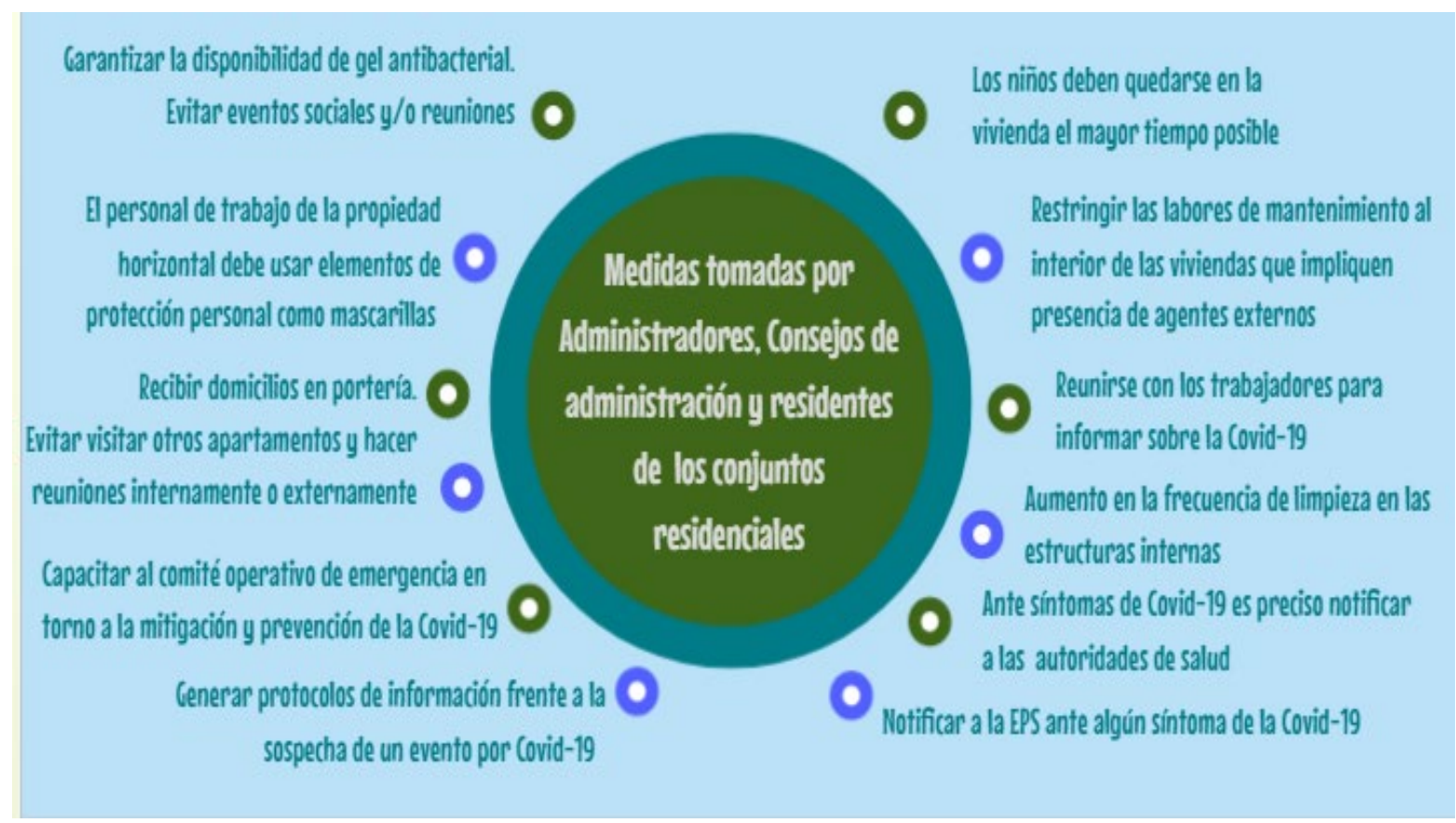

Fuente: elaboración propia.

Según el análisis de la información obtenida, se evidencian situaciones sociales, como la carencia de recursos para sobrevivir en el confinamiento, tal como lo menciona Pérez (2020), esta situación quedó demostrada para el mes de abril/2020 en la ciudad de Bogotá con el uso de los trapos rojos identificados extendidos por sectores de estrato 1,2 y 3 , siendo esta una señal de llamado de auxilio ante la vulnerabilidad económica, que demuestra la pobreza y miseria que se expande en la ciudad. También, se hicieron evidentes las situaciones discriminatorias y de estigmas instaurados en las medidas de aislamiento físico, de allí, que se discrimine al contagiado o aquella persona que tenga relación directa con el virus; incluso, como lo manifiestan los autores Gutiérrez-Avendaño y Botero-Jaramillo (2020), el uso masivo de tecnologías para el manejo de la COVID-19, con la obligatoriedad de los ciudadanos de informar sobre algún contagio, contacto con el virus, a través de la aplicación Corona APP5, manteniendo en este tipo de herramientas nuevas formas de control en las racionalidades.

Otra dificultad fue la implementación de mayores restricciones de movilidad e interacción social a ciertos grupos poblacionales considerados como vulnerables o con mayor facilidad para contraer el virus, entre ellos se encuentran el adulto mayor, niños-

5 Aplicación oficial del Gobierno Nacional de Colombia. 
Reyes-García y Molina-Ortiz

jóvenes, migrantes, privados de la libertad, por identidad de género o por condición de salud (diabetes, hipertensión, obesidad, problemas respiratorios, otros). Teniendo en cuenta lo anterior, el aislamiento físico obligatorio afectó a los adultos mayores, como lo referencian los autores Galeano-Marín, Zuluaga-Callejas y Saldarriaga-Ruiz (2020), se reconoce dentro del ciclo vital el edadismo, como una forma de discriminación, prejuicio contra las personas mayores, ignorando la heterogeneidad del adulto mayor.

En consonancia con las situaciones expuestas anteriormente, la COVID-19 se integra en la vida diaria de los individuos y la comunidad que pertenece a los conjuntos residenciales; de esta forma, cuando el virus llega a los mismos se ubica inicialmente en la organización, amenazando la estructura de sus decisiones, reglas, valores, conocimientos y capacidades.

En este sentido, los conjuntos acogen acciones mitigantes frente a la COVID-19, desde los discursos políticos que a su vez cobijan acciones basadas en el control, dando en este sentido una voz superior a las entidades y personal de la salud. Como lo expresa Borrillo (2020) "el confinamiento, control masivo de la población y distribución de mascarillas se toman en función de lo que los epidemiólogos aconsejan" (p.3), sin tener en cuenta la vivencia de una comunidad, excluyendo las narrativas de vida de las personas, siendo estas experiencias significantes en el relato histórico y de la identidad colectiva, como lo sostienen Ricouer y Arendt (citados en Quintero-Mejía, 2018).

Lo expresado anteriormente lleva a cuestionar actuaciones dentro de estos espacios, así como las experiencias que se han vivido y hacen parte directa e indirecta de la forma en que cada persona establece sus vínculos sociales, ya sean familiares, amigos, grupos, comunidades, entre otros; por lo tanto, el ser humano al ser un ser social, ha tenido que generar otras formas para mantener el contacto con sus relaciones, vínculos o redes, las cuales varían en "diversidad de intensidad de la relación y distintas posiciones relativas a lejanía o cercanía” (Campos-Vidal, 1996, p. 4). Así pues, las diferentes situaciones enunciadas a nivel social fueron asumidas por las personas que habitan el territorio, transformando la cotidianidad de los mismos, poniendo en cuestión esos cambios en los vínculos sociales durante la COVID-19.

\section{Referentes conceptuales}

\subsection{Comunidad}

Reconociendo el panorama dado por la COVID-19, aquí se identifica la comunidad, de acuerdo con Crespo-Alambarrio (2015), como el "conjunto de personas unidas por lazos de parentesco, políticos, económicos, religiosos y sociales, que comparten un espacio geográfico común” (p. 16). Además, López de Aguileta et al. (1990) tienen intereses y lazos 
comunes, incluso una interacción que define la acción comunitaria, por este motivo, está compuesto por 4 elementos: territorio, población, demanda y recursos.

De este modo, la comunidad correspondiente al estudio cuenta con aspectos mencionados anteriormente; a su vez, ésta se ubica en la zona urbana de la ciudad de Bogotá, por lo tanto, se distingue como una comunidad de tipo urbano caracterizada por tener una función política, contar con intercambios comerciales, instituciones y organizaciones sociales heterogéneas (Weber, Martindale \& Neuwirth, 1958). También, se reconoce que en una ciudad existen múltiples comunidades y relaciones grupales las cuales propician nuevos conocimientos, saberes y experiencias; asimismo, esta comunidad es acogida por los autores Lang \& Danielsen (1997), como una comunidad cerrada, puesto que allí se ubican los conjuntos residenciales. En esta línea, interpretando al autor Lazar (1999), la comunidad cerrada es aquella que ofrece una buena ubicación o servicios básicos, además de brindar las asociaciones de propietarios privados que se unen para defender intereses comunes; de igual forma, gradualmente da espacio a comunidades que se encierran en algunos sectores de la ciudad, bajo un sentimiento de inseguridad junto al temor a las amenazas externas.

En este sentido, la autora Roitman (2004), considera el conjunto residencial como aquel que se encuentra en un área urbana residencial, privatizando por ley el uso de las calles, plazas, parques que se ubican en el perímetro residencial; estos espacios sólo pueden ser usados por los residentes. Incluso, cuenta con dispositivos de vigilancia y seguridad mientras que los residentes cumplen con funciones ejecutivas, algunas legislativas o judiciales, estas se evidencian en la administración de los conjuntos, el establecimiento, cumplimiento y juzgamiento de normas de los códigos de convivencia también expuestas en la Ley 675/2001.

Por otra parte, se identifica que en ellas se encuentran familias unifamiliares de propiedad privada individual junto a otros edificios y espacios de uso común colectivo, como se evidencia también en Colombia bajo la Ley 675/2001, en el Art.63 manifiesto en el título Unidades inmobiliarias Cerradas.

\subsection{Vínculos sociales}

El término de los vínculos sociales se fundamenta en la propuesta de Serge Paugam, por ello, interpretando a Paugam (2008) el vínculo proporciona a los individuos dos elementos para el ámbito social: primero, la "protección", siendo este el conjunto de soportes que el individuo puede movilizar frente a los diversos cambios de la vida (recursos familiares, profesionales, sociales, comunitarios...); además, usa la expresión "contar con" la cual resume lo que el individuo puede esperar en torno a su relación con las instituciones y con los otros en términos de protección; segundo, el "reconocimiento" remite a la 
Reyes-García y Molina-Ortiz

interacción social que estimula al individuo a proveer la prueba de su existencia y de su valor a través de la mirada del otro o de los otros, con la expresión "contar para" que manifiesta la expectativa sobre el reconocimiento.

Lo anterior contiene una implicación afectiva reflejada en el término del "nosotros", este corresponde a la esfera con la cual y para la cual la persona sabe que puede contar; de este modo los vínculos que aseguran a la persona reconocimiento y protección adquieren una dimensión afectiva que refuerza las interdependencias humanas.

De esa manera, Paugam (2012) plantea la existencia de cuatro tipos de vínculo sociales, los cuales se describen a continuación:

- Vínculo de filiación: relaciona dos dimensiones, la primera la filiación llamada "natural", fundada sobre un reconocimiento de parentesco, donde cada individuo nace en una familia y encuentra desde el nacimiento una familia ampliada a la que pertenece sin que la haya elegido, la segunda la filiación "adoptiva", como parte de la ubicación familiar. Así, este vínculo, constituye el fundamento absoluto de pertenencia social con una función identitaria y socializadora. Brindando al individuo desde su nacimiento protección cercana (cuidados físicos) y contar con la solidaridad intergeneracional; de igual forma, el reconocimiento de contar para sus padres y sus hijos, así como el reconocimiento afectivo.

- Vínculo de participación electiva: esta se orienta a la socialización externa a la familia, su contacto con otras personas o instituciones, la cual se propicia desde diversos escenarios: la vecindad, los grupos de amigos, las instituciones religiosas, culturales, entre otras. De esta manera, integrarse conduce al ser humano a conformar por sí mismo una red de pertenencias en donde afirma su personalidad junto a la mirada de los otros. Este vínculo se mantiene en la libertad propia para seleccionar un ámbito de pertenencia, relacionando así una protección cercana (cuidados físicos) y el contar con la solidaridad y reconocimiento afectivo de contar para la pareja, amigos, vecinos, personas elegidas, y otras.

- Vínculo de participación orgánica: se fundamenta en el desempeño del trabajo y del aprendizaje (entre actores de la vida profesional), en ella cada individuo cuenta con características particulares frente a las asociadas a los otros; no obstante, aunque hay pluralidad de facultades, cada ser humano, aporta y ocupa una posición en la sociedad. Por lo tanto, este vínculo se constituye desde la escuela y se amplía durante la vida en el mundo del trabajo. Este último es de vital importancia puesto que acoge las acciones desempeñadas sobre responsabilidades otorgadas; por ende, la protección implica la existencia de un seguro laboral, un empleo estable o la protección contractual; así como, un reconocimiento por el trabajo y la estima social que de este se deriva. 
- El vínculo de ciudadanía: descansa sobre el principio de pertenecer a un Estado, como ciudadanos con derechos y deberes, sin que desaparezcan las desigualdades sociales y económicas. Acogiendo así al Estado social de derecho desde una protección a los derechos humanos, que son un anclaje entre el ciudadano y su principio de igualdad. Por esta razón, este vínculo se basa también en el reconocimiento de la soberanía del ciudadano en su independencia y autosuficiencia.

Dichos tipos de vínculos sociales son susceptibles de opresión, ruptura, como lo refieren las palabras de Paugam (citado en Consejo de Desarrollo de la Eurometrópolis de Estrasburgo, 2019):

- Están en ruptura los vínculos cuando los individuos tienen poco reconocimiento y protección.

- Los vínculos oprimen por falta de reconocimiento o protección presentando una relación que sofoca.

- Los vínculos presentan una ruptura en el trabajo cuando hay ausencia de un contrato duradero.

Así pues, se presentan en la Tabla 1 los puntos claves de la ruptura y opresión de los 4 tipos de vínculos sociales expuestos por Paugam (2008):

Tabla 1. Ruptura y opresión de los vínculos sociales.

\begin{tabular}{|c|c|c|}
\hline & Déficit de protección & Negación de reconocimiento \\
\hline Vínculo de filiación & $\begin{array}{l}\text { Imposibilidad de contar con los padres } \\
\text { o los hijos en caso de dificultad }\end{array}$ & $\begin{array}{l}\text { Abandono, malos tratos, } \\
\text { desacuerdo duradero, rechazo } \\
\text { Sentimiento de no contar para } \\
\text { los padres o los hijos }\end{array}$ \\
\hline $\begin{array}{l}\text { Vínculo de participación } \\
\text { electiva }\end{array}$ & Aislamiento relacional & $\begin{array}{l}\text { Rechazo del grupo de pares } \\
\text { Traición, abandono }\end{array}$ \\
\hline $\begin{array}{l}\text { Vínculo de participación } \\
\text { orgánica }\end{array}$ & $\begin{array}{l}\text { Vínculo ocasional con el mercado de } \\
\text { empleo, paro de larga duración, } \\
\text { entrada en una carrera de asistido }\end{array}$ & $\begin{array}{l}\text { Humillación social } \\
\text { Identidad negativa } \\
\text { Sentimiento de inutilidad }\end{array}$ \\
\hline Vínculo de ciudadanía & $\begin{array}{l}\text { Alejamiento de los circuitos } \\
\text { administrativos, } \\
\text { Incertidumbre jurídica, } \\
\text { Vulnerabilidad respecto a } \\
\text { las instituciones, } \\
\text { Ausencia de documentos de identidad, } \\
\text { Exilio forzado }\end{array}$ & $\begin{array}{l}\text { Discriminación jurídica } \\
\text { No reconocimiento de los } \\
\text { derechos civiles, políticos y } \\
\text { sociales. } \\
\text { Apatía política }\end{array}$ \\
\hline
\end{tabular}

Fuente: Paugam, 2008. La ruptura de los vínculos sociales. 
Reyes-García y Molina-Ortiz

En este orden de ideas, los vínculos sociales aportan una mirada significativa que posibilita percibir los cambios que se presentan en cada uno de los tipos de vínculos que están inmersos en la coyuntura de la COVID-19.

\subsection{La COVID-19}

Para la presente investigación es de gran importancia enunciar la COVID-19 como una enfermedad que interfiere en la vida cotidiana de la población, produciendo cambios en los vínculos sociales; percibiendo en una primera instancia a nivel clínico la COVID-19, como un nuevo tipo de neumonía causada por una infección viral, por lo cual, interpretando a la OMS (2020a), la enfermedad por el coronavirus es la COVID-19; mientras que el nombre del virus es SARS-Cov-2, estos nombres se eligieron a causa de la relación genética que presenta con el coronavirus del 2003 SARS, aunque son 2 virus diferentes.

En esta línea, la COVID-19 se concibe y reconoce en el presente estudio como una sindemia, por lo cual, se referencia el término acuñado en los años 90 con el antropólogo Singer (citado en BBC News Mundo, 2020); en sus palabras “dos o más enfermedades interactúan de forma tal que causen un daño mayor que la mera suma de estas dos enfermedades". Dicha perspectiva se complementa con el autor Kenny (citado en BBC News Mundo, 2020), el cual afirma que si la COVID-19 se asume como sindemia no solo se mira la enfermedad infecciosa sino que se tendrá en cuenta el contexto social de las personas; de modo tal que, retomando a los autores Singer, Bulled, Ostrach y Mendenhall (2017), la sindemia reúne las enfermedades crónicas no transmisibles, la desnutrición, los trastornos mentales, la exposición a tóxicos, visualizándose con más fuerza en las condiciones de desigualdad en el acceso a la salud, por la estigmatización, los bajos recursos económicos, la violencia estructural y el estrés.

\section{Metodología}

El estudio se fundamenta en el paradigma comprensivo e interpretativo, el cual, parafraseando a Pérez (citado en Ricoy-Lorenzo, 2006), es visto como el intento de comprender la realidad, desde el reconocimiento de la persona como un intérprete de la realidad, desde sus voces e intersubjetividad.

Según lo expuesto, el estudio se orienta desde la corriente filosófica del interaccionismo interpretativo, esta es relatada por Denzin (citado en Sucre-González y Cedeño-González, 2019) quien acoge la triangulación múltiple; a su vez, considera este proceso de interacción como una imagen sensibilizadora, calificándolo desde su objetivo en la explicación de la mirada del sujeto junto a su grupo social y del contexto donde coexisten; aportando en el significado que se relata en la cotidianidad de la población de los conjuntos residenciales. 
Reyes-García y Molina-Ortiz

Asimismo, la investigación es de corte cualitativo; interpretando a JiménezDomínguez (citado en Salgado-Lévano, 2007), este enfoque parte del supuesto de que el mundo social está conformado por símbolos y significados, donde la intersubjetividad es la base.

El tipo de investigación es una metodología narrativa cuya base es el estudio de la experiencia humana desde el relato, como lo determina Clandinin (citado en Blanco, 2011), quien afirma que "los argumentos para el desarrollo y uso de la investigación narrativa provienen de una óptica de la experiencia humana en la que los seres humanos, individual o socialmente, llevan vidas que pueden historiarse" (p. 139); para ello, se reconoce a los sujetos como fuente principal de la narración, permitiendo establecer una comunicación bidireccional y, desde allí, comprender las narraciones socio históricas dadas en la realidad y cómo éstas se transforman en una coyuntura social.

Además, se acoge una muestra voluntaria de las personas que convergen en los conjuntos residenciales Casablanca etapa II y Arboleda I, obteniendo de forma presencial (6) entrevistas semiestructuradas, (2) escritos autobiográficos, (9) diarios de campo y, de manera virtual, fotografías junto a conversaciones por la plataforma digital WhatsApp con 227 integrantes.

Para analizar, de forma concreta, se hace la conversión de toda la información identificando la lógica presente en los datos, seguido de una saturación, reducción, determinación de patrones, hasta llegar a tejer relaciones que vayan acorde a lo planteado (Bonilla-Castro y Rodríguez-Sehk,2005).

\section{Hallazgos}

\subsection{Vínculo filial}

Residir en un espacio específico con la familia durante la COVID-19, permite identificar diversas formas de vincularse, detectando cambios en la interacción, la rutina familiar y los cuidados físicos e intergeneracionales; en este sentido, se recalcan los sentimientos de protección en torno al cuidado físico de sus seres queridos, puesto que

No puede uno tener ese acercamiento de las personas con el cariño y aprecio con el que lo hacían anteriormente; muchos de los familiares temen por toda esa ola de comentarios que hacen, sobre todo la forma en la que se puede contagiar, de transmitir el virus. (Hombre 3, residente. Entrevista individual $)^{6}$

6 A fin de facilitar la lectura, se enunciará solamente la técnica y tipo de informante, y se omitirá información sobre fecha y forma. 
Reyes-García y Molina-Ortiz

Además, se tienen en cuenta aquellos familiares que se localizan en otras zonas, siendo imposible el contacto físico, estableciendo de esta manera estrategias comunicativas desde medios tecnológicos, perpetuando el contacto con los familiares, reflejando el cuidado del otro, principalmente, en la protección intergeneracional, la cual está marcada por la representación de los lazos de parentesco, junto a la mirada de que este ciclo vital que necesita ser sobreprotegido y sobrecuidado, dado que

cambia la forma de interactuar con la familia, pues la comunicación es generalmente más por WhatsApp y por teléfono. Sí, hay más unión entre las familias, yo nunca había extrañado tanto a mi papá como ahora (...). (Mujer 6, residente. Entrevista individual)

Así, se retoma la solidaridad entre padres, hijos, nietos, reconociendo la relación de cuidado entre los mismos, evidenciado la preocupación de acompañarlos, haciendo uso siempre de las medidas de bioseguridad, como lo expresa la siguiente vivencia: "(...) también cuidar a los abuelos, adultos mayores no dejarlos solos, cuidarlos, los llamaba por teléfono, era responsable de usar tapabocas, lavar manos(...)" (Relato autobiográfico). En esta medida, se identifica un desasosiego ante los adultos mayores, colocándolos como centro de atención en las familias, teniendo en cuenta la percepción y las cifras divulgadas por el Ministerio de Salud y protección social (2020a) ante el contagio y fallecimiento por la COVID-19 en esta población.

Por otra parte, las rutinas de los integrantes de la familia constatan situaciones que llevaron a procesos de introspección, posibilitando reflejarse en el otro, percibiendo una interacción constante en el mismo espacio físico, transportando la vida social al espacio privado en la rutina familiar, visto que

(...) no me imaginé que tendría que estar encerrada durante tanto tiempo: vivimos en un apartamento de 49 [metros] que solo tiene un baño y teníamos que aprender a cocinar, hacer aseo y estudiar, todo al mismo tiempo. Ahora todo se tenía que hacer en el mismo espacio y las rutinas se destruyeron. (Relato autobiográfico)

Estas rutinas transformadas se visualizan desde lo afectivo ya que permiten a los miembros de la misma familia llegar a acuerdos ante los cambios que experimentan, como lo interpreta López (2020). En la rutina no todo es malo, ni aburrido, por el contrario, retomar lo que se hacía antes permite identificar lo que hace falta, en especial, centrarse en las responsabilidades externas de la casa y no dentro de ella; logrando formas, estrategias de sobrellevar las situaciones cotidianas de cada uno durante la coyuntura, como aprender algo nuevo,

(...) en la pandemia [hace referencia a la pareja] aprendió a cocinar, es una pasión de él (risas) y en la pandemia eso era puros videos YouTube, (...). (Mujer 6, residente. Entrevista individual). 
Reyes-García y Molina-Ortiz

Aunque la mayoría de las rutinas fueron destruidas, esto permitió a las familias repensar la interacción, la unión que existe entre ellos, llegando al logro de acuerdos y el sentimiento de nosotros previsto en la generación de estrategias para sobrellevar la COVID19. Para finalizar, se da relevancia al cuidado como parte esencial de los sujetos en la vinculación familiar, así, el cuidado expresa que se debe ser consciente del cuidado hacia sí mismo, considerando las necesidades, deseos, sentimientos que llegamos a experimentar (Gil-Bermejo, 2016), posibilitando el cuidado a los demás, presente en los espacios de comunicación virtual durante la emergencia sanitaria.

\subsection{Vínculo de participación electiva}

Otro espacio de socialización es la vinculación dada entre amigos, vecinos, personas de la comunidad, que inciden en la vida cotidiana de los sujetos; de esta manera, se reconoce en un primer momento, la red social conformada por los amigos; no obstante, la mayoría de esta red se encuentra de manera presencial en zonas externas a los conjuntos residenciales, visto que “(...) no podemos visitar amigos, familiares, ya que todos están en otras zonas de Bogotá" (Relato autobiográfico).

Por otra parte, las fake news emergen como aquella información que condiciona, regula la manera de vincularse con los vecinos y miembros de la comunidad, tomando parte activa en la vida cotidiana; por ejemplo, la siguiente noticia falsa: “Zhong Nanshan (un neumólogo chino que descubrió el coronavirus del SARS en 2003) sugirió formas simples de prevenir la neumonía de Wuhan: Se recomienda enjuagarse la garganta con agua salada ligera antes de ir al hospital u otros lugares (...)". (Observación participante conversación WhatsApp).

Cabe mencionar la fragilidad que generó la COVID-19 ante un mundo globalizado e hiperconectado, dicha regulación y condicionamiento en los vínculos, se intensifican con el distanciamiento físico, puesto que hay una saturación de información transmitida por los dispositivos digitales sobre la sindemia, que genera confusión reflejado en la salud mental, al anunciar cifras del virus, teorías conspirativas o métodos falsos para prevenir el contagio por el grupo de WhatsApp del conjunto residencial Casablanca etapa II, intensificándose en los meses de marzo, abril y mayo del 2020.

Consecuentemente, surgen en los individuos llamados a la calma y la responsabilidad, para ser conscientes de los datos divulgados, guiándose por el Ministerio o Secretaría de salud, Corona App y las declaraciones de los gobernantes, por otro lado, se vislumbra que dicha información ocasionaba indiferencia o despreocupación hacia los vecinos y/o personas de la comunidad presentando así un déficit de protección con un aislamiento relacional, evidenciado en que "mis vecinos son pues cada uno, en su casa, si de pronto el saludo(...)" ( Mujer 6, residente. Entrevista individual). En este sentido, la información brindada por los medios tecnológicos presenta lo externo, refuerzan la sensación en el sujeto 
Reyes-García y Molina-Ortiz

de homogeneidad con su pensamiento, sin considerar las diferencias, el contexto y las múltiples aristas que abarcan un suceso (Han, 2017) como la COVID-19.

En relación con lo anterior, también se proyecta una negación de reconocimiento con la exclusión si otra persona no cumple con las medidas de bioseguridad, llevando a culparlos de las medidas restrictivas que toma el gobierno, considerando que existe un enemigo invisible que acecha como es la enfermedad de la COVID-19, y las personas se excluyen para no perjudicar el diario vivir, excusando dichas conductas bajo el precepto de evitar la transmisión del virus, denunciando que "Porque todo el mundo(...), está en el gym del parque (...),si llegara la policía a ver qué hacen todos los irresponsables". (Observación participante conversación WhatsApp).

El aislamiento relacional y la exclusión contrastan con propuestas individuales que invitan en este tiempo al cuidado, la solidaridad en la comunidad, encontrando entre ellos la capacidad de compartir necesidades e intereses, por ejemplo, el servicio de internet que se vuelve una necesidad básica para la realización de las actividades diarias en la casa, igualmente para poder relacionarse e interactuar con los otros: "está un poquito congestionado porque todo el mundo [está] en la casa" (Hombre 4, residente. Entrevista individual).

Asimismo, el valor de la solidaridad en el aspecto de protección es acuñada a la perspectiva que la sindemia es un momento difícil para todos, dado que, “(...) son tiempos difíciles, pero si todos nos cuidamos saldremos adelante recordemos no salir del apartamento si no es necesario, el bienestar es de todos" (Observación participante conversación WhatsApp) no obstante, esto se permea por la baja participación en los conjuntos ante iniciativas de solidaridad, esto se venía dando antes de la COVID-19 y se agudiza en ese tiempo.

Del mismo modo, en la interacción virtual se acentúan mensajes de esperanza, encontrando que "Dios en todo tiene un propósito. Aprovechemos los momentos de aislamiento para reflexionar en familia y unidos cuidar a nuestros niños, adultos mayores, cuidarnos todos, (...)". (Observación participante conversación WhatsApp), tomando las creencias individuales acerca de la vida, vivir un nuevo día y el descubrimiento interno como una forma de cuidarse durante la COVID-19.

En suma, al interior de los conjuntos residenciales, se presenta una tensión entre las situaciones individuales y, lo que se percibe a nivel general, la cual se traslada a la asamblea de copropietarios, distinguiendo en ella la importancia que se le da al cumplimiento de las cuotas administrativas, excusándose en tener recursos para hacerle frente a la COVID-19, convirtiéndose en una obligatoriedad. De esta forma, conduce a regular la cotidianidad de las personas que convergen en el espacio, sin considerar las particularidades o situaciones 
Reyes-García y Molina-Ortiz

complejas de algunos de los residentes, “(..) otros [hablando de los residentes], se la pasan pidiendo préstamos o haciendo acuerdos de pago, sobre todo para cancelar la administración" (Relato autobiográfico).

En este camino, los dispositivos, personal de seguridad y el administrador regulan el cumplimiento de las medidas de bioseguridad, guiándose por las normas decretadas por el gobierno, dado que en los conjuntos residenciales "los guardas de seguridad se encargan de la toma de temperatura o proporcionan gel para poder ingresar a los conjuntos, ellos toman los datos de los visitantes y los domicilios o entregas tendrán que esperar en la portería o afuera (...)" (Observación participante).

Por otra parte, el administrador acoge las sugerencias, quejas, reclamos y juzga a nivel interno a los residentes que no sigan las normas; incluso, controla el acceso de las zonas comunes, llegando a que los niños, adolescentes, adultos mayores, personas en general, en sus momentos de ocio se concentren al interior de los apartamentos, enunciando que "en una parte pues ya nadie salía, el parque tocó cerrarlo porque los niños no podían estar y la plazoleta igual, ya nadie podía estar por ahí, ni los niños". (Mujer 2, trabajadora del conjunto. Entrevista individual). Por lo tanto, regula la cotidianidad, que se justifica bajo la premisa del cuidado general, volviéndose coercitiva, limitante, el control de los cuerpos de las personas que convergen en el espacio.

\subsection{Participación orgánica}

Durante la COVID-19 se pasa de la presencialidad educativa a la educación virtual, que no tiene calidad, distinguiendo una educación tradicional acomodada a mecanismos tecnológicos, solo se brinda información sin generar un proceso intersubjetivo reflexivo en la construcción de conocimiento, limitándose al envío de tareas o trabajos:

\footnotetext{
En la educación se repite lo mismo, pero no hay calidad, creen que por un computador aprenden mucho, pero cómo hacen para que una niña de 10 años sola aprenda lo que dice la profesora si se distrae o no entiende y no se anima a preguntar. He visto a papás haciendo de profesores y haciéndoles la tarea que luego envían por correo, algunos profesores en la clase que tuvo mi hija no le explicaban bien o iban muy rápido, la veía sola mirando videos o intentando comprender algún tema. Solo una vez lloró cuando estaba presente, y así queremos que sean buenos estudiantes, algunos padres no han podido dedicarles tiempo a sus hijos, los jóvenes y niños colocan videos o juegan a escondidas cuando deberían estar estudiando. (Relato autobiográfico)
}

Por otra parte, el trabajo durante la COVID-19 en las personas se gesta desde la presencialidad encontrando un déficit de protección, con el empleo independiente, éste se acentúa en el cierre de negocios o por prestación de servicios respaldados por honorarios, como lo manifiestan el siguiente relato: "Uno es independiente, con esto se cerró tanto el negocio. (Hombre 4, residente. Entrevista individual)". Además, el trabajador debe pagar 
Reyes-García y Molina-Ortiz

su seguridad social, en ellos no se cuenta con contratos duraderos o la posibilidad de una estabilidad, detallando un cese de actividades productivas, llegando a buscar ingresos a través de trabajos informales, acarreando una afectación en la salud mental en la persona por la incertidumbre laboral y la preocupación que esto produce, en vista de que "después de superar el miedo de quedarme sin trabajo y optar por unas vacaciones que no se podían disfrutar, viendo series sin verlas y completamente asustada por los efectos del virus" (Relato autobiográfico).

Se percibe la pobreza en la población afectada por el confinamiento, como lo relatan en la revista del Centro de Estudios sobre Desarrollo Económico (CEDE, 2020), los hogares de ingreso medios y bajos tienen una mayor dependencia del ingreso monetario de trabajos asociados con sectores vulnerables a la coyuntura social, en definitiva, aquellos sectores frágiles a las consecuencias de las cuarentenas obligatorias y el aislamiento físico.

De igual modo, el reconocimiento se entrevé en las relaciones de trabajo que se rigen por las medidas de bioseguridad junto a la vigilancia reiterativa de las actividades a desarrollar en el espacio de trabajo, como "estar pendiente de los compañeros que sí estuvieran con las normas de bioseguridad"(Mujer 2, trabajadora del conjunto. Entrevista individual). Esto se contrapone con la búsqueda de apoyo entre los habitantes del conjunto residencial que cuentan con pequeños negocios y así tener un ingreso, puesto que "los vecinos deciden colocar letreros en la portería sobre la venta de tapabocas, comida, alimentos o servicios" (Observación participante); también permite hacer uso del medio tecnológico, de la red social WhatsApp para impulsar y potencializar la economía solidaria dentro de la comunidad.

\subsection{Vínculo de Ciudadanía}

Las reflexiones de los sujetos ante las actuaciones del Estado Colombiano durante la COVID-19 giran en torno a un déficit de protección teniendo en cuenta las desigualdades por la corrupción por algunos servidores públicos y el olvido estatal, encontrando territorios que no tienen donde atender pacientes con COVID-19 u otras enfermedades, con la negligencia del gobierno para responder ante la emergencia sanitaria, evidenciado en la tardanza en cerrar fronteras, como lo exponen los participantes del estudio al afirmar que "si se hubiesen cerrado fronteras, cuando este Presidente estaba buscando una columna de humo ante las denuncias en contra, lo del fraude electoral y demás, prefirió generar muertes antes que lo enjuiciaran. Eso se llama indolencia" (Observación participante conversación WhatsApp).

Además, "el aguante", expresión generalmente usada como resistencia ante una crisis social, bien sea económica, política, de género, de salud, un aguante ante el capitalismo que arrasa poblaciones, territorios en busca de incrementar a toda costa la productividad junto 
Reyes-García y Molina-Ortiz

a las ganancias dadas en el extractivismo, la vulneración de los derechos laborales y la corrupción en la prestación de los servicios sociales básicos.

En relación a lo anterior, no toda la población es discriminada ante las políticas neoliberales, por el contrario, se resalta una brecha de clases sociales que se añade al alce de la voz en la clase media ante las irregularidades de las acciones de la clase dirigente. En sus voces, se enuncia la desigualdad que arrasa el confinamiento, mencionando que "el subsidio de vivienda que sale a decir Duque a las 6 de la tarde no alcanza para los arriendos, servicios; ni las hojas de vida las aceptan para un trabajo, no hay quién compre, (...)" (Relato autobiográfico).

Por tanto, la COVID-19 agudiza y demuestra la fragilidad de la lógica capitalista, incrementando el desasosiego en la población que se nutre con la crisis económica que ya venía atravesando el país, resaltando las luchas, descontento e ira (Uribe-Tirado, Gallón, Monterroza-Ríos, Quintero-Posada y Vélez-Cuartas, 2020), puesto que, antes del virus en la cotidianeidad, países como Chile o Colombia vivían procesos de lucha como la protesta por las condiciones precarias de vida y del continuo asesinato de líderes sociales.

Al otro lado, a nivel distrital los habitantes solicitan más medidas de control para enfrentar la COVID-19, enunciando que "la alcaldía de Kennedy debería tomar medidas puesto que es de las localidades con más cifras de contagiados" (Observación participante conversación WhatsApp). De igual forma, para que se cumplan, recurren a la policía como ente del orden; no obstante, se refleja una negación de reconocimiento desde la apatía gubernamental junto a la desconfianza en la política e instituciones, lo cual polariza a las personas, entre tres caminos, primero, el considerado "mano firme" plasmado en denotar la disciplina social ante el castigo de quien incumpla las medidas, segundo aludir a la conciencia, considerando que "mano firme no...lo que hace mucha falta es conciencia (-) $\mathcal{~}$ " (Observación participante conversación WhatsApp). Por último, percibir que la mejor forma para cuidarse y controlar el cumplimiento de las medidas de bioseguridad es a través de la misma comunidad.

\section{Conclusiones}

El proceso de investigación permitió resaltar las múltiples voces que se reconocen en un contexto marcado por la sindemia de la COVID-19; incluso, identificar las experiencias en torno a vínculos sociales en sus aspectos de protección y reconocimiento, junto a la resignificación de estos, entrelazando la familia, amigos, vecinos y miembros de la comunidad durante una coyuntura social como la COVID-19.

Así, en el vínculo de filiación, la protección a nivel intergeneracional brinda una visión del ciclo de vida que rodea a los adultos mayores, la forma de acompañarlos y como son 
Reyes-García y Molina-Ortiz

percibidos en los conjuntos residenciales. No obstante, hay que ampliar la mirada en los efectos de la Covid-19 en niños, jóvenes, madres, relaciones de pareja, otros. Por otra parte, a nivel familiar considerar la forma en que los miembros comparten un mismo espacio y donde las rutinas transformadas implican una introspección que en algunos casos puede orientarse hacia la integración junto al logro de acuerdos, que pueden ser facilitadoras para la realización de acciones diarias de la cocina o de aseo.

En relación con lo anterior, también la COVID-19 propició entre las personas una saturación de información que condujo a un uso extenuante de los dispositivos y plataformas digitales, reflejadas en las fake news, las cuales inciden en la vinculación de participación electiva de los sujetos, ya que no se podía controlar la transmisión de la información, afectando con ello la salud mental. Sin embargo, enuncian la necesidad de protegerse para intentar frenar la hiperconectividad, basándose en la regulación de la información que genera pánico, recalcando la importancia de una enseñanza integral en las comunidades en torno la utilización de herramientas y plataformas tecnológicas. Lo anterior sumado al déficit de protección por la exclusión de los demás al no cumplirse las normas básicas de bioseguridad; esto redunda en una desconfianza hacia el otro, de allí que deba restablecerse una actitud de cuidado mutuo que permita unirse y vivir en paz.

Por otro lado, estos conjuntos residenciales definen su actuar siguiendo las indicaciones dadas por el gobierno y recomendaciones expuestas por las organizaciones del conjunto (administradores), resaltando las nuevas formas de comunicación, como la creación de grupos de WhatsApp y asambleas virtuales; no obstante, no son suficientes para una buena convivencia, integración o vinculación, cruzándose simultáneamente con la limitación del uso de áreas comunes. Asimismo, se dejan de lado alternativas sociales individuales que pueden contribuir a la creación de los lazos de solidaridad, cooperación e interacción entre miembros de la comunidad; así emergen los mensajes de esperanza como un elemento que indirectamente permite la vinculación con el otro, dando significado a la palabra, con expresiones positivas sobre la vida, una forma para resistir la situación actual y para el futuro.

De esta forma, los vínculos en la participación orgánica muestran un déficit de protección ante la ausencia de recursos para sobrevivir al confinamiento, teniendo en cuenta la carencia económica, poniendo toda la fuerza de trabajo y responsabilidades sociales en el mismo trabajador pues las empresas no estaban preparadas para el uso de las tecnologías. La mayoría de los sectores económicos cierran, por ello, hay que evaluar las diversas aristas del trabajo.

Aunque los sujetos buscan apoyo entre los miembros de la comunidad para su negocio o tener algún ingreso con posibilidades de subsistencia, esto no es muy visible; por ello, sería interesante dilucidar nuevas formas económicas para estos espacios. Otro punto 
Reyes-García y Molina-Ortiz

importante es la educación y su calidad, puesto que los procesos intersubjetivos, se vuelven un desafío para las familias y los estudiantes de los conjuntos que siguen procesos de educación en un estilo tradicional, de modo tal que se necesita proyectar formas para mejorar estos procesos, desde un acompañamiento personalizado a los estudiantes, plataformas learning, una formación a docentes en pedagogías para el aprendizaje virtual, cambios en la forma de evaluar en las instituciones, etc.

Adicionalmente, en el vínculo de ciudadanía se determina que el déficit de protección y negación de reconocimiento lleva a una percepción de desconfianza en el gobierno, donde las decisiones que toman los dirigentes no responden a las necesidades ni a las situaciones que vive la población, generando descontento hacia los diferentes entes estatales; este punto permite repensar la interrelación que se da con el Estado y las nuevas formas de vinculación provenientes hacia una renovación estructural.

Por otra parte, así la sindemia de la COVID-19 continúe, las sociedades seguirán transformándose de tal manera que, de forma paralela a la era digital, la corporalidad, el espacio, el encuentro físico seguirán siendo aspectos importantes en las relaciones; por ello, se debe buscar un equilibrio entre lo tecnológico y lo presencial.

Ahora bien, se plasmarán a continuación algunas consideraciones para el Trabajo Social dado que los hallazgos denotan algunos aspectos que pueden contribuir a su futuro teórico y práctico, como la importancia de recuperar y exponer las historias narradas por los sujetos manteniendo una conexión directa con la originalidad de cada obra y su lugar de enunciación, destacando la investigación narrativa desde una comunicación bidireccional, para acceder a experiencias subjetivas que llevan a una interpretación intersubjetiva de la situación, condensándose en la comprensión de las narraciones que se transforman y pueden hacer un cambio en tiempos de coyuntura social.

Cabe resaltar que desde la disciplina se deben contemplar los recursos tecnológicos, especialmente la internet, como una necesidad básica de los sujetos, dado que es un elemento que transforma la vida, está presente en los vínculos sociales, y posibilita la creación de narrativas. Por otro lado, es oportuno abrir nuevos espacios de debate frente a postulados del cuidado no dominante ante el ciclo de vida, dado que es un campo amplio y se acentúa en estos tiempos; de la misma manera, vislumbrar que el Trabajo Social en vivienda se encuentra en aspectos generales de mejoramiento o acceso a las viviendas, sin considerar singularidades como en las propiedades horizontales; por ende, es necesario trabajar con las organizaciones internas junto a los habitantes de las mismas, de forma/a fin de que propicien estrategias para mejorar la calidad de vida y los vínculos de los sujetos, encontrando con ellos formas para repensar situaciones como las que se plasman en la sindemia de la COVID-19. 
Reyes-García y Molina-Ortiz

Se recalca la importancia de comprender desde Trabajo Social que la diversidad de narrativas posibilita a la profesión ir de acuerdo con los cambios sociales, donde la comprensión de situaciones mediante las voces de las vivencias y experiencias en momentos de emergencia brindan luces sobre formas de intervenir o accionar dentro de los contextos particulares del país, sin olvidar la realidad colombiana permeada por la indiferencia, violencia y desigualdad.

En este sentido, aparece la necesidad de que los profesionales reconozcan aquellas comunidades que desean dar su voz, contradiciendo a la tradición cientificista comunicada por las instituciones y el imaginario que se brinda a la población que en ocasiones responde solo a una mirada sesgada de la realidad; como ejemplo, los conjuntos residenciales participantes en este estudio que desde sus relatos comparten realidades que la sociedad no se ha detenido a escuchar.

\section{Referencias bibliográficas}

Alcaldía Mayor de Bogotá. (2020a). Propiedad horizontal: algunas recomendaciones para prevenir el COVID-19. Recuperado de https://bogota.gov.co/miciudad/salud/coronavirus/coronavirus-recomendaciones-copropietarios-depropiedad-horizontal.

Alcaldía Mayor de Bogotá. (2020b). Simulacro Vital se extiende hasta el martes y empalmará con cuarentena nacional. Recuperado de https://bogota.gov.co/miciudad/salud/coronavirus/ simulacro-vital-se-extiende-hasta-el-martes-en-bogota.

Amezquita-Torres, F. C. (2020). Trabajo Social, emociones políticas y ética del cuidado en tiempos de Covid 19. El discurso como cuidado en la salud mental. Margen. Recuperado de https://www.margen.org/pandemia/textos/amezquita.pdf.

Andreatta, M., Navarro, A., y Pezzetta, S. (2020). Pandemia por COVID-19: Un punto de partida para pensar las intersecciones entre especismo, medioambiente y alimentación. Question/Cuestión, 1(junio), e355. doi: 10.24215/16696581e355.

Bai, Y., Yao, L., Wei, T., Tian, F., Jin, D., Chen, L... Wang, M. (2020). Presumed Asymptomatic Carrier Transmission of COVID-19. JAMA, 323(14), 1406-1407. doi: 10.1001/jama.2020.2565.

BBC News Mundo. (14 de octubre de 2020). Covid-19: qué es una pandemia y por qué hay científicos que proponen llamar así a la crisis del coronavirus. Recuperado de https:/ / www.bbc.com/mundo/noticias-54543375.

Blanco, M. (2011). Investigación narrativa: una forma de generación de conocimientos. Argumentos, 24(67), 135-156. Recuperado de http://www.scielo.org.mx/pdf/argu/v24n67/v24n67a7.pdf.

Bonilla-Castro, E., y Rodríguez-Sehk, P. (2005). Más allá del dilema de los métodos. La investigación en Ciencias Sociales. Colombia: Universidad de los Andes/Grupo Editorial Norma. 
Reyes-García y Molina-Ortiz

Borrillo, D. (2020). Foucault y la pandemia. Recuperado de https://hal.archivesouvertes.fr/hal-02564321v2/document.

Cámara de Comercio de Bogotá [CCB]. (s.f.). Definición UPZs. Recuperado de http://recursos.ccb.org.co/ccb/pot/PC/files/3definicion.html.

Campos-Vidal, J. F. (1996). Redes y el trabajo social. Taula: quaderns de pensament, (25-26), 29-37.

Recuperado

de https:/ / www.raco.cat/index.php/Taula/article/download/70969/89931.

Canal Capital. (2020). En la localidad de San Cristóbal gerencian la COVID-19. Recuperado de https:/ / conexioncapital.co/en-la-localidad-de-san-cristobal-gerencian-la-covid-19/.

CDC COVID-19 Response Team. (2020). Severe Outcomes Among Patients with Coronavirus Disease 2019 (COVID-19) - United States. MMWR Morb Mortal Wkly Rep, 69(12), 343-346. doi: 10.15585/mmwr.mm6912e2.

Centro de Estudios sobre Desarrollo Económico [CEDE]. (2020). Efectos en pobreza y desigualdad del Covid-19 en Colombia: un retroceso de dos décadas. Nota macroeconómica, (20). Recuperado de https:// uniandes.edu.co/sites/default/files/asset/document/notamacro20.pdf.

Congreso de Colombia. (4 de agosto de 2001). Régimen de propiedad horizontal [Ley 675 de 2001]. DO: 44.509.

Consejo de Desarrollo de la Eurometrópolis de Estrasburgo. (2019). Lien social. Quels enjeux et quels leviers sur le territoire de l'eurométropole? Recuperado de https://www.strasbourg.eu/documents/976405/1086315/Contribution-LienSocial-20190128.pdf/b11ca30b-2a7a-d30d-a3a7-170299a82a56.

Consejo Nacional de Población. (2010). Índice de marginación por localidad 2010. México: CONAPO. Recuperado de https://www.gob.mx/cms/uploads/attachment/file/671850/Indice_de_marginaci on_por_localidad_2010.pdf.

Coronavirus Colombia. (2020). Acciones tomadas por el Gobierno. Recuperado de https:/ / coronaviruscolombia.gov.co/Covid19/acciones-del-gobierno.html.

Crespo-Alambarrio, M. A. (2015). Guía de diseño de proyectos sociales comunitarios bajo el enfoque del Marco Lógico. (Compendio de conceptos esenciales y aplicaciones). Recuperado de https://planificacionsocialunsj.files.wordpress.com/2017/10/guia-de-proyectossociales-crespo.pdf.

Echeverry-Velásquez, M. L., y Prada-Dávila, M. (2017). Gobernabilidad y desobediencia civil en unidades inmobiliarias cerradas residenciales (UICR). Una experiencia de gobierno privado en un multifamiliar de la ciudad de Cali. Revista Eleuthera, 16, 32-53. Recuperado de http:/ /190.15.17.25/eleuthera/downloads/Eleuthera16_3.pdf.

Fradejas-García, I., Lubbers, M. J., García-Santesmases, A., Molina, J. L., y Rubio-Ros, C. (2020). Etnografías de la pandemia por coronavirus: emergencia empírica y resignificación social. Periferia, revista de recerca i formació en antropologia, 25(2), 4-21. doi: $10.5565 /$ rev/periferia.803. 
Reyes-García y Molina-Ortiz

Galeano-Marín, M. E., Zuluaga-Callejas, M. I., y Saldarriaga-Ruiz, G. J. (2020). Envejecimiento y Covid-19: los debates que impone el confinamiento de los mayores a un mundo envejeciente. En Uribe, A., Yarce, A., De la Torre, A., Monterroza, A., Quintero, A., Pérez, A. ... Osorio, Y. (2020). Polifonía para pensar una pandemia (pp.145165). Medellín, Colombia: Universidad de Antioquia, Fondo Editorial FCSH de la Facultad de Ciencias Sociales y Humanas. Recuperado de http:/ / bibliotecadigital.udea.edu.co/bitstream/10495/17635/4/UribeAlejandro_20 20_PolifoniaPensarPandemia.pdf.

Gil-Bermejo, J. (2016). El cuidado en la intervención social. Una práctica en la ética del Trabajo Social. En D. Carbonero, E. Raya, N. Caparros y C. Gimeno (Coords), Respuestas transdisciplinares en una sociedad global. Aportaciones desde el Trabajo Social (p. 133). España: Universidad de La Rioja. Recuperado de: https:/ / publicaciones.unirioja.es/catalogo/online/CIFETS_2016/Monografia/pdf/ TC363.pdf.

González-Serna, A. (2016). Del habitar en solidaridades entre poblaciones que viven del trabajo, a la vida en conjuntos residenciales urbano-rurales. PROSPECTIVA. Revista de Trabajo Social e intervención social, (21), 241-260. doi: 10.25100/prts.v0i21.927.

Gutiérrez-Avendaño, J., y Botero-Jaramillo, N. (2020). Comunidad inmunitaria y excepción de la vida en tiempos de pandemia. En Uribe, A., Yarce, A., De la Torre, A., Monterroza, A., Quintero, A., Pérez, A. ... Osorio, Y. (2020). Polifonía para pensar una pandemia (pp.91-110). Medellín, Colombia: Universidad de Antioquia, Fondo Editorial FCSH de la Facultad de Ciencias Sociales y Humanas. Recuperado de http:/ / bibliotecadigital.udea.edu.co/bitstream/10495/17635/4/UribeAlejandro_20 20_PolifoniaPensarPandemia.pdf.

Han, B. Y. (2017). La expulsión de lo distinto. Barcelona: Herder.

He, F., Deng, Y., \& Li, W. (2020). Coronavirus disease 2019: What we know? Journal of Medical Virology, 92(7), 719-725. doi: 10.1002/jmv.25766.

Lang, R., \&. Danielsen, K. (1997). Gated communities in America: Walling out the world? Housing Policy Debate, 8(4), doi: 10.1080/10511482.1997.9521281.

Lazar, G. (1999). L'essor des villes fortifiées. À propos de Fortress America: Gated Communities in the United States. Futuribles, (243). Recuperado de https:// www.futuribles.com/en/revue/243/lessor-des-villes-fortifiees-a-proposde-fortress-/.

López de Aguileta, I., García Roca, J., Marchioni, M., Puche, F., Gil, S., Renes, V. ... Arnanz, E. (1990). El voluntariado en la acción sociocultural. Madrid: Editorial Popular.

López, J. S. (11 de mayo de 2020). [Fotoperiodismo] Y cambiamos la rutina. Directo Bogotá. Recuperado de https:/ / www.directobogota.com/post/la-rutinacambio.

Martínez-Toro, P. M. (2016). El conjunto residencial cerrado como tipología urbanística instrumentalizada por la financiarización. PROSPECTIVA. Revista de Trabajo Social e intervención social, (21). doi: 10.25100/ prts.v0i21.919. 
Reyes-García y Molina-Ortiz

Mesa, M., y Alonso-Cano, L. (2020). Narrativas y discursos en tiempos de pandemia: como explicar la crisis del COVID-19 desde el feminismo pacifista. Recuperado de https:/ / ceipaz.org/wp-content/uploads/2020/05/6.2020-ManuelayLaura.pdf.

Ministerio de Salud y Protección Social. (2020a). Coronavirus (Covid-19). Reportes y Tableros de Control. Recuperado de https:/ / www.minsalud.gov.co/salud/publica/PET/Paginas/Covid-19_copia.aspx. Ministerio de Salud y Protección Social. (2020b). Colombia confirma su primer caso de COVID19. Recuperado de https://www.minsalud.gov.co/Paginas/Colombia-confirma-suprimer-caso-de-COVID-19.aspx.

Muñoz-Rojas, O. (19 de octubre de 2020). No es una pandemia, es una sindemia. El País. Recuperado de https://elpais.com/opinion/2020-10-19/no-es-una-pandemia-esuna-sindemia.html.

Organización Mundial de la Salud [OMS]. (2020a). Los nombres de la enfermedad por coronavirus (COVID-19) y del virus que la causa. Recuperado de https://www.who.int/es/emergencies/diseases/novel-coronavirus2019/technical-guidance/naming-the-coronavirus-disease-(covid-2019)-and-thevirus-that-causes-it.

Organización Mundial de la Salud [OMS]. (2020b). Zoonosis y medio ambiente. Áreas de trabajo. Recuperado de https:/ / www.who.int/foodsafety/areas_work/zoonose/es/.

Organización Panamericana de la Salud [OPS]. (2020). COVID-19: Materiales de comunicación. Recuperado de https://www.paho.org/es/covid-19-materiales-comunicacion.

Ospina, Y., Peña, L., Ramírez, M., Real, K., Riveros, D., y Rojas, S. (2020). Afectación del Covid19 en Bogotá D.C. Recuperado de https://www.researchgate.net/profile/DianaRiveros-3/publication/341606326_Covid19_involvement_in_Bogota_DC/links/5ec9e5ba92851c11a884f3d8/Covid-19involvement-in-Bogota-DC.pdf.

Paugam, S. (2008). Le lien social. París. Paris: PUF.

Paugam, S. (2012). Protección y Reconocimiento. Por una sociología de los vínculos sociales. Papeles del CEIC, 2(82). doi: 10.1387/pceic.12453.

Pérez, A. L. (2020). Los trapos rojos ondean en el cielo: reflexiones sobre precariedad y resistencia en la pandemia. En Uribe, A., Yarce, A., De la Torre, A., Monterroza, A., Quintero, A., Pérez, A. ... Osorio, Y. (2020). Polifonía para pensar una pandemia (pp. 215235). Medellín, Colombia: Universidad de Antioquia, Fondo Editorial FCSH de la Facultad de Ciencias Sociales y Humanas. Recuperado de http:/ / bibliotecadigital.udea.edu.co/bitstream/10495/17635/4/UribeAlejandro_20 20_PolifoniaPensarPandemia.pdf.

Pleyers, G. (2020). Los movimientos sociales y la batalla por el significado de la crisis del coronavirus. Revista Pensamiento y Acción Interdisciplinaria, 6(1). doi: 10.29035/pai.6.1.108.

Presidencia de la República de Colombia. (2020). El Aislamiento Preventivo Obligatorio se extiende hasta el 15 de julio, anuncia Duque. Recuperado de 
Reyes-García y Molina-Ortiz

https:/ /id.presidencia.gov.co/Paginas/prensa/2020/Aislamiento-Preventivo-

Obligatorio-se-extiende-hasta-el-15-de-julio-anuncia-Duque-200623.aspx.

Quintero-Mejía, M. (2018). Usos de las narrativas, epistemologías y metodologías: aportes para la investigación. Bogotá, Colombia: Universidad Distrital Francisco José de Caldas. Recuperado de https://www.academia.edu/40262813/Usos_de_las_narrativas_epistemolog\%C3\% ADas_y_metodolog\%C3\%ADas_Aportes_para_la_investigaci\%C3\%B3n.

Rezende, J. M. de. (1998). Epidemia, endemia, pandemia. Epidemiología. Revista de Patología Tropical/Journal of Tropical Pathology, 27(1). doi: 10.5216/rpt.v27i1.17199.

Ricoy-Lorenzo, C. (2006). Contribución sobre los paradigmas de investigación. Educação. Revista do Centro de Educação, 31(1), 11-22. Recuperado de https:/ / www.redalyc.org/pdf/1171/117117257002.pdf.

Rincón-Salazar, M. T. (2018). La convivencia vecinal en unidades residenciales de Cali, Colombia. Un análisis cualitativo con modelo multidimensional. Entramado, 14(1), 214-229. doi: 10.18041/entramado.2018v14n1.27116.

Rodríguez, E. G. (2020). Coronavirus: conexiones ocultas, narrativas entretejidas. Recuperado de http:/ / www.academia.edu/download/62536879/Coronavirus_conexiones_ocultas 20200329-79440-hpl2sk.pdf.

Roitman, S. (2004). Urbanizaciones cerradas: estado de la cuestión hoy y propuesta teórica. Revista de geografía Norte Grande, (32), 5-19. Recuperado de: https:/ / www.redalyc.org/articulo.oa?id=30003201.

Roitman, S. (2016). Urbanizaciones cerradas a escala planetaria. PROSPECTIVA. Revista de Trabajo Social e intervención social, (21). doi: 10.25100/prts.v0i21.918.

Salgado-Lévano, A. (2007). Investigación cualitativa: diseños, evaluación del rigor metodológico y retos. Liberabit, 13(13), 71-78. Recuperado de http://www.scielo.org.pe/pdf/liber/v13n13/a09v13n13.pdf.

Sardiña, M. (7 de junio de 2020). Kennedy: sobrepoblación e informalidad en el epicentro de la pandemia en la capital de Colombia. France 24 . Recuperado de https://www.france24.com/es/20200607-kennedy-epicentro-pandemia-covid19colombia.

Singer, M., Bulled, N., Ostrach, B., y Mendenhall, E. (2017). Syndemics and the biosocial conception of health. THE LANCET. 389(10072), 941-950. doi: 10.1016/S01406736(17)30003-X.

Sucre-González, L., y Cedeño-González, J. A. (2019): Una mirada distintiva a la tendencia investigativa cualitativa: interaccionismo simbólico Revista Atlante: Cuadernos de Educación y Desarrollo, (marzo), 1-16. Recuperado de https:/ / www.eumed.net/rev/atlante/2019/03/tendencia-investigativacualitativa.html.

TRT. (2020). Inicia una nueva cuarentena estricta en algunas localidades de Bogotá. Recuperado de https://www.trt.net.tr/espanol/espana-y-america- 
Reyes-García y Molina-Ortiz

latina/2020/07/13/inicia-una-nueva-cuarentena-estricta-en-algunas-localidades-debogota-1454249.

Uribe-Tirado, A., Gallón, L., Monterroza-Ríos, Á., Quintero-Posada, A., y Vélez-Cuartas, G. (2020). Datos, información, conocimiento: otra cruel pedagogía del virus. En Uribe, A., Yarce, A., De la Torre, A., Monterroza, A., Quintero, A., Pérez, A. ... Osorio, Y. (2020). Polifonía para pensar una pandemia (pp. 67-87). Medellín, Colombia: Universidad de Antioquia, Fondo Editorial FCSH de la Facultad de Ciencias Sociales y Humanas. Recuperado de http:/ / bibliotecadigital.udea.edu.co/bitstream/10495/17635/4/UribeAlejandro_20 20_PolifoniaPensarPandemia.pdf.

Velavan, T. P., \& Meyer, C. G. (2020). The COVID-19 epidemic. Tropical medicine $\mathcal{E}$ international health, 25(3), 278-280. Recuperado de https:/ / www.ncbi.nlm.nih.gov/pmc/articles/PMC7169770/pdf/TMI-25-278.pdf.

Vidal-Koppmann, S. (2001). Segregación residencial y apropiación del espacio: la migración hacia las urbanizaciones cerradas del Área metropolitana de Buenos Aires (Argentina). Scripta Nova, 94(70), 1-17. Recuperado de https://www.ungs.edu.ar/cm/uploaded_files/file/ubyd/base_ico_docs/icosseeuu/SSEEUU-2001-A-175.pdf.

Weber, M., Martindale, D., \& Neuwirth, G. (1958). The city. Glencoe, Escocia: Free Press. 


\section{OTROS ARTÍCULOS DE PROSPECTIVA No. 33}

\section{EDITORIAL}

El Paro Nacional en Colombia 2021: explosión social entre dinámicas estructurales y de coyuntura. Relevancia de la acción política y del diálogo en su desarrollo y transformación Adolfo Adrián Álvarez-Rodríguez

\section{ARTÍCULOS}

Organizaciones sociales de pobladores y prácticas de resistencia en contexto de pandemia COVID-19 en Chile

Patricia Castañeda-Meneses

Entre el aislamiento y las brechas digitales: sistematización de experiencia de acompañamiento socioemocional en personas mayores de Temuco, Chile, en tiempos de COVID-19

G. Bernarda Aedo-Neira

Percepción de apoyo social y calidad de vida: la visión de personas mayores chilenas en el contexto de pandemia durante el 2020

Claudia Elena Quiroga-Sanzana

Gabriela Rocío Parra-Monje

Camila Julia Moyano-Sepúlveda

Marco Alejandro Díaz-Bravo

A propósito del qué, cómo y para qué investigar en el campo de la justicia juvenil: La trastienda de un proceso de investigación en Rosario, Argentina Karina De Bella

Proyección social: reflexión sobre una experiencia virtual con adolescentes en época de pandemia en Sucre y Bolivar, Colombia

Claudia Yaneth Martínez-Mina
La intervención social mediante proyectos comunitarios en modalidad virtual en Mérida, México. Una perspectiva desde el Trabajo Social Claudia Isabel Tzec-Puch Amairani Aracelly Ceh-Alvarado Yanet Guadalupe González-Canul

Resignificación de los vínculos Sociales durante la pandemia de COVID-19: narrativas de personas que convergen en Conjuntos residenciales en Bogotá, Colombia

Andrea Marcela Reyes-García

Laura Daniela Molina-Ortiz

La paradoja de la familia doblemente recluida: clínica de una pandemia en Colombia

Norman Darío Moreno-Carmona

Juan José Cleves-Valencia

Ciencias sociales, mundo y pandemia: por un futuro posible

José Miguel Segura-Gutiérrez

Lina Paola Vásquez-Ávila

¿Qué es Trabajo Social? Los primeros vínculos de los estudiantes con la profesión: experiencias de Argentina, Brasil, Paraguay y Uruguay

Silvia Orieta Rivero-Rodríguez

Leonel Del Prado

Nidia Graciela Battilana-Amarilla

Rosilaine Coradini-Guilherme

Intervención profesional de trabajadores sociales de la universidad del Quindio, Colombia. Asuntos epistemológicos, metodológicos y ético-políticos

Ana María Gil-Ríos 
Reflexiones sobre la intervención social en lo rural: experiencias en el Magdalena Medio, Colombia

Claudia Milena Quijano-Mejía

Johana Linares-García

Construcción de rutas de atención integral a la convivencia escolar en Cali, Colombia: sistematización de la experiencia

Leidy Johana Prado-Montaño

Luz Helena López-Rodríguez

Alejandra Gutiérrez-Cárdenas

Experiencia del proceso de intervención familiar de los actores participantes en la Escuela para Familias del ICBF-Jamundí, Colombia Katherin Viviana Silva-Minotta

María José Forero-Izquierdo

Jimena del Pilar Jaramillo-Jaramillo

\section{RESEÑAS DE LIBROS}

Alerta global: políticas, movimientos sociales y futuros en disputa en tiempos de pandemia Jairo Crispín

El neoliberalismo como teología política. Habermas, Foucault, Dardot, Laval y la historia del capitalismo contemporáneo

José Francisco Desentis-Torres

La Reconceptualización del Trabajo Social en Colombia: Análisis histórico-crítico de las décadas de 1960-1970

Juan Pablo Sierra-Tapiro

ARTISTA INVITADO

Juan Camilo González

Prospectiva

\section{PROSPECTIVA}

Revista de Trabajo Social e Intervención Social

No. 33 • ene.-jun. 2022

e-ISSN: 2389-993X • Universidad del Valle 